\title{
PENTINGNYA LABIRIN BAGI IKAN RAWA
}

\author{
Asyari \\ Peneliti pada Balai Riset Perikanan Perairan Umum, Mariana-Palembang
}

Teregristrasi I tanggal: 15 September 2006; Diterima setelah perbaikan tanggal: 21 Pebruari 2007; Disetujui terbit tanggal: 20 April 2007

\begin{abstract}
ABSTRAK
Perairan rawa yang terdiri atas rawa pasang surut dan rawa lebak, merupakan habitat yang baik bagi ikan sebagai tempat mencari makan, tempat mengasuh anak, dan tempat memijah. Perairan rawa memiliki karakteristik fisik, kimia, dan biologi yang khas, pada umumnya banyak terdapat tumbuhan air, kandungan $\mathrm{O}_{2}$, dan $\mathrm{pH}$ rendah, sebaliknya $\mathrm{CO}_{2}$ relatif tinggi, karena banyak terjadi proses dekomposisi. Jenis-jenis ikan yang mendominasi perairan rawa adalah ikan-ikan yang mempunyai alat pernafasan tambahan (labirin), sehingga dapat mengambil oksigen langsung dari udara. Jenis ikan tersebut, disebut ikan hitam (black fish) seperti tembakang (Helostoma temmincki), betok (Anabas testudineus), sepat siam (Trichogaster pectoralis), sepat rawa (Trichogaster trichopterus) dan lain-lain. Labirin terletak di bagian atas rongga insang, terdiri atas lapisan-lapisan kulit yang berlekuk-lekuk dan mengandung banyak pembuluh darah. Ada organ labirin merupakan bentuk penyesuaian terhadap kondisi jelek di suatu perairan, terutama pada kondisi oksigen rendah di saat musim kemarau.
\end{abstract}

KATAKUNCI: labirin, perairan rawa, ikan hitam

\section{PENDAHULUAN}

Indonesia mempunyai perairan rawa seluas 39,4 juta ha terdiri atas rawa pasang surut 24,7 juta ha dan rawa lebak 14,7 juta ha (Suwarno et al., 1990). Perairan tersebut tersebar di Sumatera, Kalimantan, Sulawesi, dan Irian Jaya. Rawa pasang surut adalah semua lahan daratan yang menerima pengaruh langsung dari perubahan tinggi air laut pada waktu pasang, mulai dari arah pantai (hilir) dengan air yang asin sampai dengan kedaratan (arah hulu) dengan air yang tawar (Sastrakusumah, 1982). Rawa lebak atau rawa banjiran (flood plain) adalah lahan atau dataran di tepi sungai yang tergenang ketika air sungai meluap (terjadi banjir yang cukup tinggi) sehingga membentuk rawa (Hoggarth et al., 2000).

Perairan rawa memiliki karakteristik fisik, kimia, dan biologi yang khas, pada umumnya banyak ditumbuhi semak, $\mathrm{pH}$ air rendah dan kandungan $\mathrm{O}_{2}$ terlarut rendah $<5 \mathrm{ppm}$. Pada rawa yang banyak ditumbuhi pohon dan semak, produksi primer air juga rendah, karena cahaya matahari tak banyak masuk. Masukan energi hanya dari daun-daun yang jatuh, yang proses desintegrasi juga lambat, sedangkan kadar humic acid tinggi (Sastrakusumah, 1982).

Ekosistem rawa merupakan habitat yang baik bagi ikan sebagai tempat mencari makan (feeding ground), tempat mengasuh anak (nursery ground), dan tempat memijah (spawning ground), maka daerah rawa merupakan daerah yang produktif bagi sumber daya perikanan (Utomo \& Asyari, 1999).

Rawa lebak dipengaruhi oleh curah hujan dan luapan air sungai, sehingga selalu tergenang selama musim hujan dan kering di musim kemarau. Rawa lebak pada umumnya mempunyai bagian-bagian yang dalam berupa cekungan (lebung), sehingga rawa lebak juga disebut rawa lebak lebung. Lebung merupakan bagian ekosistem yang penting di rawa lebak karena merupakan tempat tinggal induk ikan saat musim kemarau. Tergantung dari tinggi air dan lama genangan, maka rawa lebak dapat dibedakan atas 3 macam, yaitu lebak dangkal dengan genangan $50 \mathrm{~cm}$ selama kurang dari 3 bulan; lebak tengahan dengan kedalaman genangan 50 sampai dengan $100 \mathrm{~cm}$ selama 3 sampai dengan 6 bulan; dan lebak dalam dengan genangan lebih dari $100 \mathrm{~cm}$ selama lebih dari 6 bulan (Ismail et al., 1990).

Menurut Ondara (1993) nilai pH rawa lebak tidak tetap sepanjang hari, ini disebabkan oleh proses fotosintesis yang terjadi siang hari dan pernafasan pada malam hari, pada rawa lebak yang berhutan gelam (Malaleuca leucadendron) terdapat potensi tanah sulfat masam dengan $\mathrm{pH}$ mencapai 3,5.

Pada rawa lebak waktu musim kemarau $\mathrm{pH}$ dan kandungan $\mathrm{O}_{2}$ terlarut sangat rendah, sedangkan $\mathrm{CO}_{2}$ tinggi, ikan-ikan yang hidup di perairan ini hanya ikanikan yang tahan dengan kondisi demikian. Jenis ikan 
yang mendominasi perairan rawa lebak adalah ikanikan yang mempunyai alat pernafasan tambahan (labirin) dari kelompok atau Ordo Labyrinthici, agar dapat mengambil oksigen dari udara bebas. Kelompok ikan tersebut oleh Welcomme (1979) disebut ikan hitam (black fish), jenis ikan hitam tersebut antara lain sepat siam (Trichogaster pectoralis), gabus (Channa striata), tembakang (Helostoma temmincki), betok (Anabas testudineus), keli (Clarias spp.), dan lain-lain.

Kebutuhan oksigen $\left(\mathrm{O}_{2}\right)$ bagi makhluk hidup dan ikan adalah suatu hal yang pasti, tak terkecuali bagi ikan-ikan rawa. Tulisan ini menguraikan bagaimana cara ikan rawa untuk memenuhi kebutuhan oksigen di saat ketersediaan oksigen tersebut sangat rendah terutama di saat musim kemarau.

\section{CIRI-CIRI PERAIRAN RAWA}

Perairan rawa adalah tipe perairan tergenang (lentic water), merupakan lahan basah atau tergenang air, berair tidak dalam, berdasarkan pada lunak, lumpur, atau tumbuhan membusuk. Kalau ada hubungan dengan sungai air mengalir lamban, kalau tidak stagnan (Sastrakusumah, 1982).

Utomo et al. (2004) mengatakan beberapa ciri perairan rawa sebagai berikut:

1. Fluktuasi tinggi air saat pasang dan surut atau saat musim penghujan dan kemarau mencapai 2 sampai dengan $5 \mathrm{~m}$.

2. Mempunyai daerah litoral yang luas, merupakan habitat yang baik bagi organisme terutama ikan.

3. Banyak terdapat vegetasi air yang merupakan sumber nutrien dan pakan bagi organisme air (feeding ground), selain itu juga merupakan tempat pemijahan (spawning ground) dan asuhan (nursery ground) bagi beberapa jenis ikan.

4. Berair dangkal, sehingga sinar matahari dapat menembus sampai dengan dasar perairan.

5. Kandungan $\mathrm{O}_{2}$ terlarut rendah, $\mathrm{pH}$ juga rendah (asam), sebaliknya $\mathrm{CO}_{2}$ relatif tinggi karena banyak terjadi proses dekomposisi.

Perairan lebak atau rawa lebak lebung (flood plain) dicirikan oleh sifat musiman (seasonility). Sifat musiman ini nampak pada perubahan tinggi air, luas permukaan air, perubahan lingkungan akuatik ke terestrial dan sebaliknya, juga produksi organisme makanan ikan, pemijahan ikan sampai dengan ke penangkapan ikan oleh nelayan (Ondara, 1993). Menurut llyas et al. (1992) ciri-ciri perairan rawa lebak lebung, selama musim hujan perairan lebak lebung bersatu dengan sungai induk, sedangkan pada musim kemarau sebagian besar perairan ini kering dan hanya bagian tertentu yang berair yaitu lebung, karena bagian yang berupa cekungan ini jauh lebih dalam, sehingga selalu berair walaupun musim kemarau.

Lebih jauh Ilyas et al. (1992) mengatakan bahwa tipe-tipe habitat lebak lebung sebagai berikut:

1. Talang, yaitu bagian tepi perairan lebak lebung, tidak terendam air, tetapi air tanah dipengaruhi oleh tinggi air di perairan lebak lebung.

2. Vegetasinya berupa hutan primer atau sekunder atau kadang-kadang perladangan atau perkebunan penduduk.

3. Rawang, yaitu bagian lebak lebung yang lahan lebih rendah dari talang.

4. Vegetasi berupa hutan rawa yang ditumbuhi hutanhutan besar. Di musim penghujan selalu terendam air dan di musim kemarau kering.

5. Lebak kumpai, yaitu bagian perairan lebak lebung yang elevasi lahan lebih rendah dari rawang. Vegetasi berupa rumput-rumputan (kumpai) dan semak belukar.

6. Sungai utama atau Batanghari yang terbagi atas bagian yang dalam disebut lubuk dan pada umumnya berarus deras, dan bagian yang dangkal disebut rantau.

7. Batas, yaitu bagian tepi sungai utama yang elevasi sedikit lebih tinggi dari lebak kumpai. Secara limnologis dan hidrologis, batas sangat penting karena menentukan waktu dan identitas proses banjir atau melimpah atau keluar air dari lebak kumpai atau rawang.

8. Alur, yaitu bagian batas yang elevasi lebih rendah sehingga membentuk semacam anak sungai yang menjadi jalan keluar masuk ikan pada saat air mulai naik atau surut.

Utomo et al. (2004) mengatakan bahwa, perairan rawa selain merupakan daerah yang produktif bagi sumber daya perikanan juga berfungsi sebagai pengendali banjir, sumber air bagi manusia, dapat mencegah erosi dan abrasi, dan juga sebagai penyerap limbah pertanian.

\section{LABIRIN DAN KEBUTUHAN OKSIGEN}

\section{Labirin}

Menurut Hoeve (1996) nama labirin diberikan karena ikan-ikan ini mempunyai alat pernafasan tambahan yaitu organ Labyrinthyang terletak di bagian atas rongga insang. Ikan-ikan ini bernafas dengan menghirup udara bebas di permukaan air. Labirin ini 
terdiri atas lapisan-lapisan kulit yang berlekuk-lekuk dan mengandung banyak pembuluh darah. Udara masuk lewat mulut dan dipompakan ke dalam organ labirin tempat terjadi pertukaran gas. Oksigen akan larut ke dalam darah dan karbondioksida $\left(\mathrm{CO}_{2}\right)$ dikeluarkan. Pada kebanyakan ikan labirin, pernafasan normal dengan insang sangat berkurang, sehingga ikan akan tenggelam apabila dihalangi muncul ke permukaan air untuk menghirup udara. Hal ini, jelas merupakan bentuk penyesuaian terhadap kondisi buruk di suatu perairan seperti di sungai yang tercemar atau rawa-rawa yang kadar oksigen rendah, terutama saat musim kemarau. Organ labirin tidak berkembang sebelum anak ikan berumur beberapa minggu, karena kebutuhan oksigen pada ikan yang belum dewasa dapat dipenuhi oleh pernafasan normal melalui insang (Hoeve, 1996).

Beberapa jenis ikan dari family Chanidae seperti ikan gabus (Channa striata) dan toman (Channa micropeltes) juga telah mengembangkan organ pernafasan tambahan pada bagian atas insang yang merupakan modifikasi dari organ labirin. Organ ini berupa bilik-bilik insang yang mempunyai kantongkantong kecil yang terlipat dan dilengkapi dengan pembuluh-pembuluh darah guna menyerap oksigen. Hal ini, menyebabkan ikan gabus mampu bergerak dalam jarak yang cukup jauh pada musim kemarau untuk mencari sumber air (Kottelat et al., 1993 ).

Selain itu, ikan belut (Monopterus albus) dari family Synbranchidae juga telah mengembangkan organ pernafasan tambahan sehingga mampu menghirup udara secara langsung dari udara (Hoeve, 1996). Udara ini kemudian disimpan dalam kantung di ujung usus yang berfungsi sebagai pembuluh darah (Kottelat et al., 1993). Tidak jarang belut dijumpai dalam parit (selokan) kecil yang sangat tercemar atau pada lubang-lubang di rawa-rawa yang dangkal.

\section{Kebutuhan Oksigen}

Oksigen merupakan faktor yang sangat penting untuk pernafasan (respirasi) organisme dan merupakan salah satu komponen utama bagi metabolisme ikan dan organisme perairan lain (Wardojo, 1975). Selain itu, ikan juga memerlukan oksigen guna pembakaran makanan (bahan bakar) untuk menghasilkan aktivitas, seperti aktivitas berenang, pertumbuhan, reproduksi, dan lain-lain. Oleh sebab itu, ketersediaan oksigen bagi ikan sangat menentukan segala aktivitas ikan (Zonneveld et al., 1991). Kebutuhan organisme terhadap oksigen sangat bervariasi tergantung kepada jenis, stadia, dan aktivitas organisme tersebut. Kebutuhan oksigen ikan yang diam relatif lebih rendah dibandingkan dengan ikan yang aktif bergerak dan memijah. Untuk kelompok ikan yang dapat mengambil oksigen bebas dari udara (breathing fishes) dapat bertahan terhadap kondisi oksigen yang rendah di suatu perairan (Wardojo, 1975).

Keberadaan oksigen terlarut dalam air dipengaruhi oleh suhu, kadar garam, tekanan parsiel gas-gas yang ada di udara maupun di air, serta ada senyawa yang mudah teroksidasi di dalam air. Makin tinggi suhu, kadar garam, dan tekanan parsiel gas yang terlarut dalam air, maka kelarutan oksigen semakin berkurang.

Menurut NTAC (1968); Pescod (1973) kandungan oksigen terlarut minimal 2 mg per I sudah cukup untuk mendukung kehidupan ikan, sepanjang tidak terdapat senyawa lain yang bersifat racun (toxic). Selanjutnya, NTAC (1968) menambahkan bahwa agar ikan dapat hidup dengan layak sebaiknya kandungan oksigen terlarut harus tidak kurang dari $4 \mathrm{mg}$ per I. Pada musim kemarau oksigen akan berkurang di perairan, karena naik suhu menyebabkan pengurangan konsentrasi oksigen di dalam air. Semakin tinggi suhu semakin meningkat metabolisme pada ikan dan organisme air lain dan semakin meningkat pula kebutuhan akan oksigen, tetapi kemampuan haemoglobin untuk mengikat oksigen berkurang (Kottelat et al., 1993).

Proses respirasi oleh organisme (ikan, zooplankton, dan mikroorganisme lain) serta proses diffusi menyebabkan kandungan oksigen berkurang, bahkan habis di suatu perairan. Namun, secara alami oksigen juga akan masuk ke perairan terutama melalui proses fotosintesis 90 sampai dengan 95\%, sedangkan yang lain melalui diffusi dari udara dan dari perairan itu sendiri (Schmittou, 1991).

\section{BEBERAPA JENIS IKAN BERLABIRIN}

Perairan rawa yang demikian luas mempunyai ikan yang sangat banyak, baik dari segi kualitas (jenis) maupun kuantitas (jumlah). Pada saat musim kemarau, di mana kondisi air tidak begitu baik $(\mathrm{pH}$ dan $\mathrm{O}_{2}$ ) rendah beberapa kelompok ikan dapat bertahan untuk hidup pada kondisi perairan yang demikian, yaitu dengan ada organ labirin (alat bantu pernafasan), sehingga ikan-ikan ini mampu mengambil oksigen secara bebas dari udara. 

lain:

Beberapa jenis ikan yang mempunyai labirin antara

1. Ikan guram atau kalui (Osphronemus goramylac) Ikan dari family Osphronemidae ini juga disebut giant gouramis (gurami raksasa) karena berukuran besar dapat mencapai $60 \mathrm{~cm}$. Merupakan ikan konsumsi penting yang semula hanya ada di Indonesia (Sumatera, Jawa, dan Kalimantan), tetapi sekarang sudah banyak di introduksi ke Asia dan Australia (Kottelat et al., 1993). Dalam keadaan alami ikan ini hidup di rawa-rawa, parit, atau sungaisungai, tetapi sekarang sudah merupakan ikan budi daya yang penting terutama di kolam-kolam. Ikan gurami mulai matang gonad umur 2 sampai dengan 3 tahun, untuk pemijahan ikan ini membuat sarang terlebih dahulu dari rumput-rumputan, sarang ini berdiameter 30 sampai dengan $38 \mathrm{~cm}$ yang ditempatkan tersembunyi di antara rumputrumputan atau tanaman air (Susanto, 1987). Larva ikan gurame menyukai jasad renik berupa Rotifera dan Infusoria, sedangkan ukuran benihnya lebih menyukai larva insekta, Crustacea, dan Zooplankton, setelah lebih dewasa menyenangi pakan berupa tumbuhan air (Susanto, 1987). Untuk menghirup oksigen langsung dari udara di kolam budi daya, ikan ini lebih sering terlihat bergerak naik turun daripada gerak horizontal, tidak jarang ikan ini ditemukan mati mengapung karena kolam tempat budi daya tertutup rapat oleh tanaman air (Susanto, 1987).

2. Ikan tembakang atau biawan (Helostoma temmincki C.V.)

Merupakan satu-satunya jenis yang termasuk family Helostomatidae (Kottelat et al., 1993). Ikan ini disebut juga gurami pencium (kissing gouramis), karena kebiasaan saling menempelkan bibir yang tebal sesama, tingkah yang tampak seolah-olah ramah ini, sebenarnya merupakan suatu ancaman dalam upaya mempertahankan hak atas teritorium atau pasangan hidup (Hoeve,
1996). Merupakan ikan yang umum dijumpai di Asia Tenggara serta merupakan ikan konsumsi, dengan panjang dapat mencapai $25 \mathrm{~cm}$. Ikan ini lebih menyukai tempat yang hangat berada pada ketinggian 150 sampai dengan $750 \mathrm{~m}$ di atas permukaan laut. Merupakan ikan pemakan plankton maupun periphyton, matang gonad dimulai pada umur 1 sampai dengan 1,5 tahun, untuk memijah ikan tembakang memilih tempat yang terlindung di rawa-rawa seperti di bawah daundaun atau tumbuhan air untuk melekatkan telurtelur (Susanto, 1987). Selain itu, tahan terhadap kadar oksigen yang rendah, telur yang cukup banyak, menyebabkan ikan ini cepat untuk berkembang biak.

\section{Ikan betok (Anabas testudineus BI)}

Ikan ini termasuk family Anabantidae, sering disebut sebagai ikan pejalan (walking or climbing fishes). Keterampilan untuk berjalan jauh di darat sudah sangat dikenal, menggunakan ekor untuk bergerak, sirip perut, sirip dada, dan tutup insang yang keras digunakan untuk mendukung bobot badan (Kottelat et al., 1993). Menurut Hoeve (1996) sebenarnya tutup insang ikan betok ini berfungsi sebagai kaki tambahan waktu ikan ini berjalan di darat, tutup insang yang berduri ini direntangkan untuk menjaga keseimbangan, sedangkan sirip dada dan sirip ekor mendorong untuk maju. Di Indonesia dan Asia Tenggara lain merupakan ikan konsumsi, dan di Kalimantan Selatan sebagai ikan konsumsi merupakan ikan kebanggaan dan disukai masyarakat dengan harga yang cukup mahal (Azizi \& Wahyudi, 2001). Sebagai ikan yang hidup di rawa-rawa ikan ini mampu bertahan hidup di luar air dalam waktu yang cukup lama, asal kulit tetap basah. Ikan betok ini dalam pemijahan menyukai tempat di rawa-rawa lebak pada habitat yang banyak ditumbuhi kumpai (Gramineae). Selain itu, ikan ini juga sering disebut ikan puyu atau papuyu (Gambar 1).

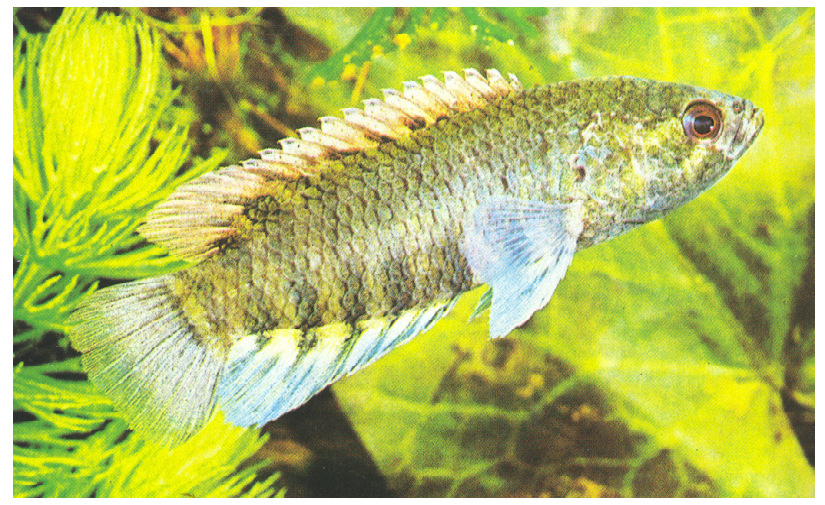

Gambar 1. Ikan betok (Anabas testudineus B). Sumber: Hoeve (1996) 
4. Ikan sepat siam (Trichogaster pectoralis reg) Ikan ini berasal dari siam (Thailand), dan diintroduksikan ke Indonesia pada tahun 1934. Sifat-sifat yang menguntungkan dari sepat siam ini telah dibuktikan berkali-kali dengan berhasil penebaran yang dilakukan di Kalimantan Selatan, Kalimantan Timur, Sulawesi Selatan, Sumatera Selatan, dan lain-lain (Ondara, 1982). Selain itu, pada tahun 1987 sepat siam sudah merupakan ikan nomor 2 terbanyak setelah ikan gabus dan merupakan $9 \%$ dari seluruh hasil tangkapan ikan perairan umum di Indonesia (Ondara, 1995). Salah satu yang menyebabkan ikan ini dapat berkembang biak demikian cepat adalah karena dapat mengeluarkan telur banyak-banyak dan dapat bertahan pada kadar oksigen yang rendah. Ikan yang suka hidup pada perairan dangkal yang bervegetasi ini mulai matang gonad pada umur 6 sampai dengan 7 bulan pada ukuran 8 sampai dengan $12 \mathrm{~cm}$, dan memijah pada musim penghujan. Untuk memijah induk jantan membuat sarang busa pada permukaan air di antara tumbuhan, 1 sarang busa dapat mengisi 7.000 sampai dengan 8.000 butir telur. Sarang busa berguna untuk melindungi telur dan untuk menjamin kadar oksigen agar tetap tinggi untuk perkembangan telur tersebut terutama pada tempat yang banyak vegetasi (Ondara, 1993).

5. Ikan sepat rawa (Trichogaster trichopterus Pal) Merupakan ikan asli Indonesia, sering juga disebut sepat Jawa, sedangkan di Sumatera Selatan disebut sepat mato merah, karena mata memang berwarna merah (Gambar 2). Sepat ini berukuran kecil antara 6 sampai dengan $7 \mathrm{~cm}$, di Indonesia juga merupakan ikan konsumsi. Sesuai nama ikan ini memang mempunyai habitat di perairan rawa terutama di rawa lebak (Patriono et al., 2005). Di Indonesia ikan sepat rawa banyak terdapat pada dataran rendah di Sumatera Selatan, Riau, Jambi, seluruh Propinsi di Kalimantan, Jawa, Sulawesi, dan Irian Jaya (Zainal, 1985). Ikan ini bersifat herbivora, di alam komposisi makanan ikan ini terdiri atas fitoplankton yaitu Bacillariophyceae, Desmidiaceae, Cyanophyceae, Clorophyceae, dan Zooplankton seperti Mastigophora, Sarcodina, dan Ciliata (Patriono et al., 2005). Untuk memijah sama seperti sepat siam ikan ini juga membuat sarang busa di permukaan air untuk menetaskan telur.

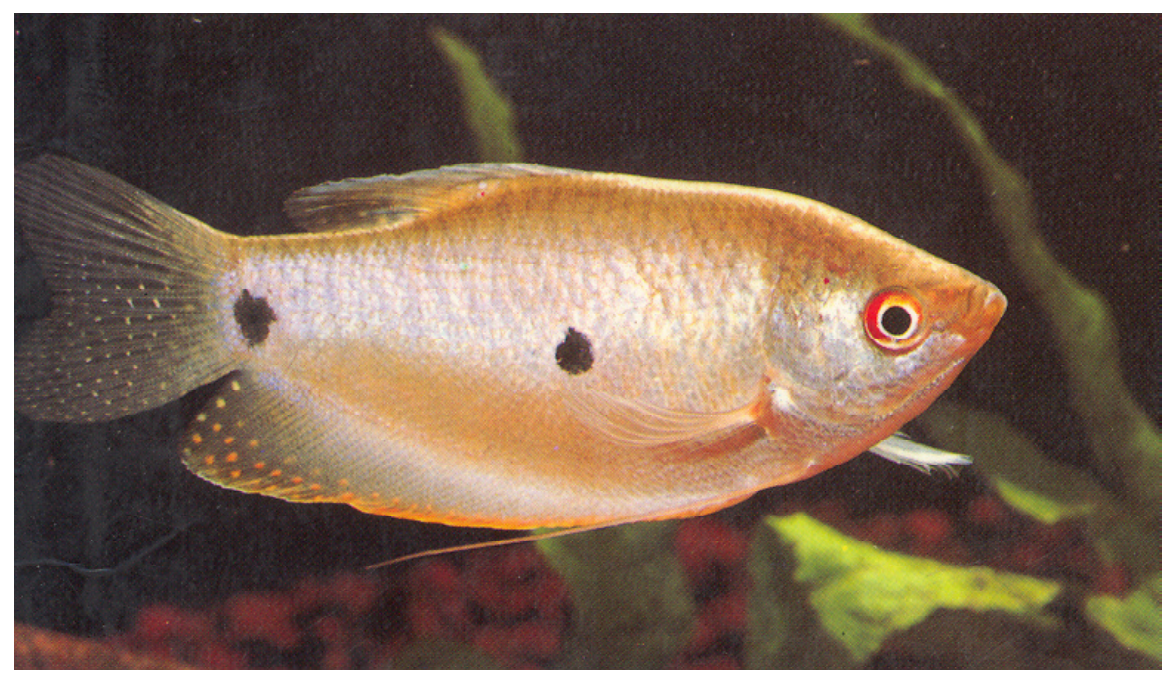

Gambar 2. Ikan sepat rawa (Trichopterus trichopterus Pall). Sumber: Kottelat et al. (1993)

6. Sepat mutiara (Trichogaster leeri Blkr)

Ikan yang umum terdapat di Indonesia, Malaysia, dan Thailand, di Indonesia banyak dijumpai di Sumatera dan Kalimantan. Ikan yang disebut juga gurami danau ini di Sumatera Selatan disebut sepat daun buluh, sedangkan di Kalimantan Tengah disebut sepat layang atau sepat batik. Mempunyai bentuk yang indah berwarna kebiru-biruan dengan suatu renda halus berupa bintik-bintik putih di sekujur tubuh (Gambar 3). Ikan yang sering dijadikan ikan hias ini termasuk family Belontiidae, bersama-sama dengan sepat siam dan dan sepat rawa (Kottelat et al., 1993). 


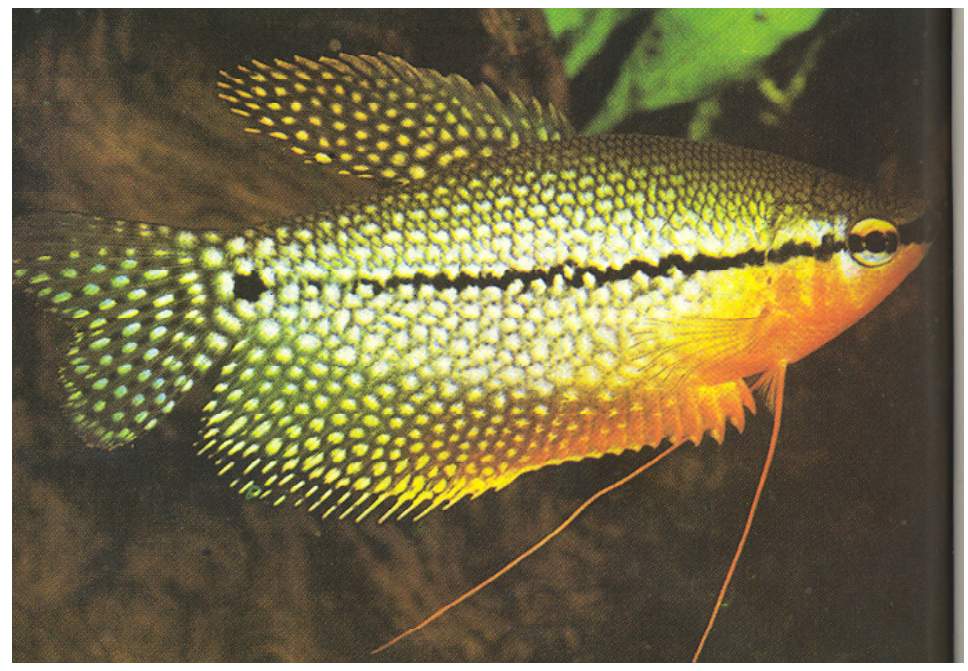

Gambar 3. Sepat mutiara (Trichopterus leeri Blkr).

Sumber: Hoeve (1996)

\section{KESIMPULAN}

Perairan rawa terdiri atas rawa pasang surut dan rawa lebak. Di Indonesia tersebar di Sumatera, Kalimantan, Sulawesi, dan Papua. Ekosistem perairan rawa merupakan habitat yang baik bagi ikan sebagai tempat mencari makan (feeding ground), tempat mengasuh anak (nursery ground), dan tempat memijah (spawning ground).

Perairan rawa memiliki karakteristik fisik, kimia, dan biologi yang khas. Banyak terdapat tumbuhan air, nilai $\mathrm{pH}$, dan kandungan oksigen yang rendah, sedangkan $\mathrm{CO}_{2}$ relatif tinggi. Jenis ikan yang mendominasi perairan rawa adalah jenis ikan yang mempunyai organ pernafasan tambahan (labirin) seperti ikan tembakang (Helostoma temmincki), betok (Anabas testudineus), sepat siam (Trichogaster pectoralis), sepat rawa (Trichogaster trichopterus), dan lain-lain.

\section{PERSANTUNAN}

Review pustaka

\section{DAFTAR PUSTAKA}

Azizi, A. \& N. A. Wahyudi. 2001. Studi kelayakan penangkapan dan pemasaran ikan betok (Anabas testudineus) di Kalimantan Selatan. Jurnal Penelitian Perikanan Indonesia. Vol.7. No.2. Pusat Riset Perikanan Budi Daya. Badan Riset Kelautan dan Perikanan. Hal: 70-78.
Hoeve, W. V. 1996. Ensiklopedi Indonesia seri fauna Ikan. PT. Ichtiar Baru Van Hoeve. 256 hal.

Hoggart, D. D., F. Sukadi, A. S. Sarnita, S. Koeshendrajana, N. A. Wahyudi, E. S. Kartamihardja, A. Poernomo, M. S. Anggraeni, A. K. Gaffar, Ondara, Samuel, M. A. Thomas, Murniyati, \& K. Purnomo. 2000. Panduan pengelolaan bersama suaka produksi ikan di perairan sungai dan rawa banjiran. Pusat Penelitian dan Pengembangan Perikanan. Badan Penelitian dan Pengembangan Pertanian. 27 hal.

Ilyas, S., E. S. Kartamihardja, F. Cholik, R. Arifudin, Krismono, D. W. Hedrotjahjo, Z. Jangkaru, W. Ismail, A. Hardjamulja, E. Pratiwi, H. Supriadi, Sutrisno, \& S. Hadiwigeno.1992. Pedoman teknis pengelolaan perairan umum bagi pengembangan perikanan. Pusat Penelitian dan Pengembangan Perikanan. Badan Penelitian dan Pengembangan Pertanian. 80 hal.

Ismail, I. G., I. Basa, P. Soetjipto, \& T. Suhud. 1990. Tinjauan hasil penelitian usaha tani lahan pasang surut di Sumatera Selatan. Usaha tani di lahan pasang surut dan rawa. Risalah Seminar Hasil Penelitian. Proyek penelitian pertanian lahan pasang surut dan rawa. SWAMP II. Badan Penelitian dan Pengembangan Pertanian. Hal.: 129.

Kottelat, M., A. J. Whitten, S. N. Kartikasari, \& S. Wiryoatmodjo. 1993. Freshwater fishes of western Indonesia and Sulawesi. Perplus Edition-EMDI Project. Jakarta. Indonesia. 293 pp. 
NTAC. 1968. Water quality criteria. FWPCA. Washington DC. 234 p.

Ondara. 1982. Beberapa catatan tentang perairan tawar dan fauna ikannya di Indonesia. Prosiding Seminar Perikanan Perairan Umum. Badan Penelitian dan Pengembangan Pertanian. Pusat Penelitian dan Pengembangan Perikanan. Hal.: 13-32.

Ondara. 1993. Pemanfaatan dan pengelolaan perikanan perairan lebak lebung. Prosiding Temu Karya IImiah Perikanan Perairan Umum. Pengkajian potensi dan prospek pengembangan perairan umum Sumatera bagian selatan. Pusat Penelitian dan Pengembangan Perikanan. Badan Penelitian dan Pengembangan Pertanian. Hal.: 89105.

Ondara. 1995. Penebaran sebagai tindakan pengelolaan perikanan perairan umum. Kumpulan makalah seminar PPEHP perikanan perairan umum. Sub Balai Penelitian Perikanan Air Tawar Palembang. Balai Penelitian Perikanan Air Tawar. Badan Penelitian dan Pengembangan Pertanian. Hal.: 12-19.

Patriono, E., D. Anggraeni, \& E. Nofyan. 2005. Studi komposisi fitoplankton sebagai pakan alami sepat rawa ( Trichogaster trichopterus Pall) stadium muda di lebak lebung Teloko Sumatera Selatan. Prosiding Forum Perairan Umum I. Pemanfaatan dan pengelolaan perairan umum secara terpadu bagi generasi sekarang dan mendatang. Pusat Riset Perikanan Tangkap. Badan Riset Kelautan dan Perikanan. Hal.: 149-153.

Pescod, M. B. 1973. Investigation of rational effluent and stream standarts for tropical countries. AIT. Bangkok. 59 p.

Sastrakusumah, S. 1982. Usaha pemanfaatan rawa dan perairan pasang surut dengan cara inkonvensional. Prosiding Seminar Perikanan Perairan Umum. Pusat Penelitian dan Pengembangan Perikanan. Badan Penelitian dan Pengembangan Pertanian. Hal.: 237-241.

Schmittou, H. R. 1991. Fish stress, health, and deseases. Short course on aquaculture technology (cage culture), 21 Januari to 9 Februari, $4 \mathrm{p}$.

Susanto, H. 1987. Budi daya ikan di pekarangan. PT. Penebar Swadaya. Anggota IKAPI. Jakarta. 152 hal.

Suwarno, Z. Harahap, \& A. Prawirosamudro. 1990. Perbaikan varietas tanaman pangan untuk menunjang usaha tani lahan pasang surut dan rawa. Usaha tani di lahan pasang surut dan rawa. Risalah Seminar Hasil Penelitian. Proyek penelitian pertanian lahan pasang surut dan rawa. SWAMP II. Badan Penelitian dan Pengembangan Pertanian. Hal.: 213-222.

Utomo, A. D. \& Asyari. 1999. Peranan ekosistem hutan rawa air tawar bagi kelestarian sumber daya perikanan di Sungai Kapuas, Kalimantan Barat. Jurnal Penelitian Perikanan Indonesia. Vol.V. No.3. Pusat Penelitian dan Pengembangan Perikanan. Jakarta. Hal.: 1-14.

Utomo, A.D., Asyari, \& K. Fatah. 2004. Peran sungai rawa sebagai pemeliharaan keseimbangan lingkungan dan tempat kehidupan ikan. Jurnal Pengelolaan Lingkungan dan Sumber Daya Alam. Diterbitkan oleh program studi pengelolaan lingkungan. Program Pascasarjana Universitas Sriwijaya. Hal.: 133-140.

Wardoyo, S. T. H. 1975. Pengelolaan kualitas air (water management). Proyek peningkatan mutu perguruan tinggi. Institut Pertanian Bogor. 38 (41) hal.

Welcomme, R. L. 1979. Fisheries ecology of flood plain rivers. Longman Groupe. Limited. London and New York. 317 pp.

Zainal. 1985. Pengaruh dasar kolam rawa-rawa yang dilapisi pasir terhadap pertumbuhan ikan sepat rawa (Trichogaster trichopterus Pall) di Balai Percobaan Perikanan Kulim Pekanbaru. Berkala Perikanan Terubuk. Th XI. No.32. Diterbitkan oleh himpunan alumni Fakultas Perikanan Universitas Riau Terubuk. Hal.: 36-54.

Zonneveld, N., E. A. Huisman, \& J. H. Boon. 1991. Prinsip-prinsip budi daya ikan. Penerbit PT. Gramedia Pustaka Utama. Jakarta. 318 hal. 